\title{
DILIGENCIAS DE ACCESO A FUENTES DE PRUEBA Y RESPONSABILIDAD FRENTE A CONSUMIDORES Y USUARIOS. UNA PERSPECTIVA COMPARADA: EE. UU., ALEMANIA Y ESPAÑA
}

\author{
DISCOVERY AND LIABILITY TOWARDS CONSUMERS. A \\ COMPARATIVE PERSPECTIVE: USA, GERMANY AND SPAIN
}

\author{
Guillermo A. Morales Sancho \\ Profesor Ayudante, Doctor Derecho Constitucional \\ Universidad de Navarra \\ Profesor Visitante \\ Westfälische Wilhelms-Universität Münster
}

Recibido: 19.05.2021 / Aceptado: 28.06.2021

DOI: https://doi.org/10.20318/cdt.2021.6265

\begin{abstract}
Resumen: El presente trabajo explica en perspectiva comparada (España, EE. UU. y Alemania) la figura de las diligencias de acceso a fuentes de prueba y su aplicación a reclamaciones de responsabilidad entabladas por consumidores y usuarios en vista de la futura transposición al ordenamiento español de la Directiva 2020/1828/EU de 25 de noviembre relativa a las acciones de representación para la protección de los intereses colectivos de los consumidores, y por la que se deroga la Directiva 2009/22/CE.

Palabras clave: diligencias de acceso a fuentes de prueba, discovery, litigación transfronteriza, acciones colectivas.
\end{abstract}

Abstract: How pre-trial discovery works in the Spanish, US and German legal systems and its comparative application in consumers' Law is the subject matter of this research. In light of this compared analysis, proposals are made for the upcoming transposition in the Spanish legal system of Directive (EU) 2020/1828 of the European Parliament and of the Council of 25 November 2020 on representative actions for the protection of the collective interests of consumers and repealing Directive 2009/22/EC.

Keywords: discovery, disclosure of evidence, access to documents, cross-border litigation, collective redress, class actions.

Sumario: I. Introducción; II. El origen de la Directiva 2020/1828; III. La efectividad del discovery estadounidense a la luz de la jurisprudencia sobre productos defectuosos: 1. Anticonceptivos hormonales de tercera generación (Drospirenona/ethynilstradiol), 2. Otros supuestos; IV. US Civil Litigation and Discovery: 1. Discovery Plan, 2. Tipos de fuentes de prueba (Discovery methods), 3. Bases de datos electrónicas (Public Access to Court Electronic Records), 4. Litigación mulidistrito para agilizar el discovery (Multidistrict Litigation Statute, 28 U.S.C.A. § 1407); V. Utilidad de la experiencia de litigación civil americana para el ordenamiento español: 1 . De lege lata: uso en un proceso español de pruebas obtenidas en un discovery americano, 2. De lege ferenda; VI. Conclusiones.

*Agradezco a d. Íker Pérez Sierra su colaboración como miembro del equipo de investigación de plataformas de afectados de Clínica Jurídica UNAV. 


\section{Introducción}

1. Las diligencias de acceso a fuentes de prueba (en adelante, DAFP) son un poderoso instrumento procesal que acaba de iniciar su andadura en el ordenamiento europeo (Directiva 2014/104) ${ }^{1}$, alemán $^{2}$ y español ${ }^{3}$ (art. 286 bis a)-k) LEC añadidos por el RDL 9/2017). Se trata de una figura afín al pre-trial discovery of documents ${ }^{4}$ de gran arraigo en la tradición anglosajona ${ }^{5}$. Se distinguen, en cambio, de las diligencias preliminares en su amplitud (abarca un amplio catálogo numerus apertus), su ámbito de aplicación, el momento procesal de solicitud, los legitimados (futuro demandante, demandante y el demandado), la tramitación procesal, el régimen de recursos y sus garantías (caución facultativa, sanciones específicas en caso de desatender las peticiones) ${ }^{6}$. Las DAFP tampoco cabe reducirlas a la exhibición de documentos de los arts. 328-334 LEC, por lo limitado de su objeto y los requisitos exigidos al solicitante ${ }^{7}$. La reciente jurisprudencia española surgida con ocasión del cártel de camiones ha sido la encargada de perfilar los contornos de esta figura ${ }^{8}$ y la que ha empezado a familiarizar a nuestra cultura jurídica con este prometedor instrumento.

${ }^{1}$ J. Malinauskaite, y C. Cauffman, «The Transposition of the Antitrust Damages Directive in the Small Member States of the EU-A Comparative Perspective», Journal of European Competition Law \& Practice, vol. 9, 8, 2018, Oxford University Press (OUP); F. MARcos, «Transposition of the antitrust damages directive into Spanish Law», Jean Monnet Working Papers IE-Law School, 2018.

${ }^{2}$ C. HeInZE, «Der kartelldeliktische Schadensersatzanspruch nach der Richtlinie 2014/104/EU - Baustein oder Fremdkörper im europäischen Haftungsrecht?», Zeitschrift für Europäisches Privatrecht, 2020; T. KöRBER y H. SCHWEITZER y D. ZIMMER, «Die Umsetzung der Kartellschadensersatz-Richtlinie», en U. Immenga, E.-J. Mestmäcker (eds.) Wettbewerbsrecht, 6, C. H. Beck, München, 2020; S. OнLноғ, «RL 2014/104/EU und Regierungsentwurf für 9. GWB-Novelle», en H.-G. KamanN, S. Ohlhoff, S. VöLcKer (eds.) Kartellverfahren und Kartellprozess, C. H. Beck, München, 2020.

${ }^{3}$ A.COHEN Benchetrit, «Una reforma procesal de calado en materia de reclamaciones derivadas de actos anticoncurrenciales», Lex Mercatoria, vol. 6, 2017; P. FerRÁndiz AvENDAÑo, «Discovery en reclamaciones de daños por prácticas restrictivas de la competencia (El nuevo artículo 283 bis LEC)», La Ley, vol. 9052, 2017; F. Gascón InCHAUSTI, «Aspectos procesales de las acciones de daños derivados de infracciones de las normas sobre defensa de la competencia: apuntes a la luz de la Directiva 2014/104 y de la propuesta de ley de transposición», Cuadernos de Derecho Transnacional, vol. 9, 1, 2017; P. GonZÁLEZ GrANDA, «La regulación del acceso a las fuentes de prueba en la Ley de Enjuiciamiento Civil: algunas sombras relativas al sistema y a su naturaleza jurídica», Justicia, 2, 2017; C. HERrero SuÁrEz, «La transposición de la directiva de daños antitrust. Reflexiones a raíz de la publicación de la propuesta de ley de transposición de la directiva», Cuadernos de Derecho Transnacional, vol. 8, 1, 2016.

${ }^{4}$ F. A. Peña González, «¿Es una forma de discovery trial la nueva prueba de los artículos 283 bis de la Ley de Enjuiciamiento Civil?», Análisis Gómez Acebo \& Pombo, 9, 2017.

${ }_{5}^{5}$ L. V. M. Bento, The Globalization of Discovery: The Law and Practice under $\$ 28$ U.S.C. 1782, Kluwer Law International, Alphen aan den Rjin, 2019; Committe on the Judiciary House of Representatives, «Federal Rules of Civil Procedure», pp. 37-63, Rules 26-37; J. N. DeMeo, y otros, California Deposition and Discovery Practice, 14, LexisNexis, Matthew Bender \& Company, Santa Rosa, California, 2020; A. Holtzoff, «Instruments of Discovery under Federal Rules of Civil Procedure», Michigan Law Review, vol. 41, 2, 1942.

${ }^{6}$ M. J. AChÓN BRUÑÉN, «Futura modificación de la LEC para la trasposición de la Directiva 2014/104/UE: medidas de acceso a fuentes de prueba, diferencias procesales con las actuales diligencias preliminares», Práctica de tribunales, vol. 125, 2, 2017; R. Castrillo Santamaría, La preparación del proceso civil: las diligencias preliminares, Bosch, Barcelona, 2018, pp. 51-65; F. Cordón Moreno, «La reclamación de daños por infracción del Derecho de la competencia. Innovaciones en materia probatoria y, en especial, la regulación del acceso a las fuentes de prueba», Análisis Gómez-Acebo \& Pombo, 2017.

7 "El artículo [328 LEC] exige los siguientes requisitos: (i) que la parte no pueda disponer del documento de ninguna otra manera; (ii) que el documento sea pertinente, ya sea por referirse a lo que es objeto del pleito, ya sea por tener relevancia para determinar el valor probatorio de otros medios de prueba. No es admisible pretender por esta vía la exhibición de documentos útiles para preparar el juicio, petición que tiene encaje en las normas sobre diligencias preliminares — SAP Valencia $\left(7^{\mathrm{a}}\right)$ 30.6.2005 (Tol 701102) - ; (iii) que el solicitante acompañe una copia simple del documento o, al menos, si no dispone de ella, que indique con la mayor precisión posible cuál es su contenido, requisito este que es esencial para que pueda producirse el efecto previsto en el artículo 329.1 LEC. Es admisible que se haga una indicación general del contenido que se atribuye al documento cuando no sea posible una mayor precisión, pero en modo alguno puede admitirse, a efectos de aplicar el artículo 329.1 LEC, que se solicite la exhibición de un documento del que no se aporta copia ni se facilita versión alguna de su contenido —SAP Madrid (14 ${ }^{\mathrm{a}}$ ) 4.11.2013 (Tol 4055076); SAP Ourense (1 $1^{\mathrm{a}}$ ) 29.2.2012 (Tol 2484448)—. Es inexcusable que la petición se refiera a documentos concretos y determinados, y no genéricos —SAP Madrid (9a) 5.12.2013 (Tol 4115664)—." J. L. Fernández Vaquero, «Artículo 328 LeC», en F. Marín Castán, Ma A. De Andrés Herrero (eds.) Comentarios a la Ley de Enjuiciamiento Civil, Tirant lo Blanch, Valencia, 2015, pp. 1518-1519.

${ }^{8}$ M. J. FernÁndez Alcalá, «El acceso a las fuentes de prueba en procedimientos de reclamación de daños por infracción del derecho de la competencia», Revista de Consumo y Empresa, vol. 12, 2020. 
2. Pues bien, tal como señalan el RDL $9 / 2017$ en el apdo. II de su exposición de motivos ${ }^{9}$ y el art. 71.2.a) $\mathrm{LDC}^{10}$, su ámbito de aplicación ${ }^{11}$ se restringe a aquellas acciones que se fundamenten en la infracción del Derecho de la competencia, en particular, las tipificadas en los arts. 1-2 LDC y 101-102 TFUE; esto es, excluyendo expresamente las prácticas desleales con consumidores del art. 3 de la LDC LD $^{12}$ - desarrolladas en los preceptos 4-5, 7-8, 19-31 de la Ley de competencia desleal-y las infracciones de la normativa de consumidores y usuarios recogidas en el TRLGDCU.

3. Paralelamente, la reciente Directiva $2020 / 1828$ de 25 de noviembre ${ }^{13}$ crea un nuevo proceso de demanda colectiva pensado para proteger los intereses colectivos de consumidores y usuarios. Con base en él, las entidades habilitadas podrán entablar acciones en las que se pretenda no sólo la cesación de las conductas infractoras del Derecho de consumo, sino también - y esta es la novedad más relevante ${ }^{14}$ — la compensación por los daños sufridos (art. 9).

4. Asimismo, los arts. 18-19 de la mencionada Directiva prevén - aunque de forma menos detallada que los arts. 5-8 de la Directiva 2014/104 aplicable a los ilícitos anticoncurrenciales de los que traen causa las diligencias de acceso a fuentes de prueba (art. 283 bis LEC) — la exhibición de pruebas para las acciones en defensa de intereses colectivos de consumidores y usuarios. España deberá transponer esta Directiva al ordenamiento interno antes del 25 de diciembre de 2022 y, en consecuencia, hacer una reforma de calado en su legislación rituaria.

5. Este trabajo tiene por objeto precisamente explorar esta figura de la "exhibición de pruebas" aplicada a las acciones colectivas de consumidores y usuarios (arts. 18-19 Directiva 2020/1828) y

9 “Al incorporar este nuevo título VI a la Ley 15/2007, de 3 de julio, de Defensa de la Competencia, se pretende también extender la nueva normativa a las reclamaciones de los daños causados por las infracciones a los artículos 1 y 2 de dicha ley que no afectan al comercio entre los Estados miembros de la Unión y que, por tanto, no entran en el ámbito de aplicación de los artículos 101 y 102 del Tratado de Funcionamiento de la Unión Europea, no así a los actos de competencia desleal que por falsear la libre competencia afecten al interés público dado que cuentan con un régimen específico en la Ley 3/1991, de 10 de enero, de Competencia Desleal."

10 " 2 . A efectos de este título:

a) Se considera como infracción del Derecho de la competencia toda infracción de los artículos 101 o 102 del Tratado de Funcionamiento de la Unión Europea o de los artículos 1 ó 2 de la presente ley." Sobre el conjunto de ilícitos anticoncurrenciales abarcados, cfr. M. Kellerbauer y M. Klamert y J. Tomkin, Commentary on the EU treaties and the Charter of Fundamental Rights, Oxford University Press, Oxford, 2019, pp. 998-1058.

${ }^{11}$ P. GonzÁlez Granda, "La regulación del acceso a las fuentes de prueba”, cit., p. 126.

${ }^{12}$ Para ellas se contemplaban las diligencias de comprobación de hechos (art. 36 LCD que a su vez se remitía a los arts. 129-132 de la derogada Ley 11/1986). Sin embargo, las sucesivas reformas del Derecho de la competencia y la inclusión de las diligencias preliminares en materia de propiedad intelectual e industrial y otras leyes especiales (art. 256.1. $7^{\circ}-9^{\circ}$ LEC) han terminado emborronando dicha referencia normativa. En consecuencia, las diligencias de comprobación de hechos han tenido un alcance muy limitado en materia de consumidores y usuarios. Cfr. A. ARMENGot VilaplanA, «Diligencias preliminares, medidas cautelares y especialidades probatorias en materia de competencia desleal», en K. Beneyto Pallás, A. ARmengot VILAPLANa (eds.) Actos de competencia desleal y su tratamiento procesal: un estudio práctico de la Ley de competencia desleal (LCD), Tirant lo Blanch, Valencia, 2020; SÁnchez Barrios, M. I., «Artículo 36 LCD. Diligencias preliminares», en A. Bercovitz Rodríguez-Cano, E. Galán Corona, I. Quintana Carlo, J. A. García-Cruces González (eds.) Comentarios a la Ley de Competencia Desleal, Thomson Reuters, Aranzadi, Cizur Menor, 2011.

${ }^{13}$ Directiva (UE) 2020/1828 de 25 de noviembre relativa a las acciones de representación para la protección de los intereses colectivos de los consumidores, y por la que se deroga la Directiva 2009/22/CE, 2020.

${ }^{14}$ Considerando 5 de la Directiva: "Para reforzar la disuasión de las prácticas ilícitas y reducir el perjuicio al consumidor en un mercado cada vez más globalizado y digitalizado, es necesario reforzar los mecanismos procesales de protección de los intereses colectivos de los consumidores, para incluir tanto medidas de cesación como medidas resarcitorias." Cursiva propia. Cfr. S. Corominas BACH, «El nuevo modelo alemán de acción declarativa (MFKG): ¿una tutela colectiva efectiva del Dieselgate?», Revista General de Derecho Procesal, vol. 49, 2019, pp. 5-6; F. GAScón Inchausti, «¿Hacia un modelo europeo de tutela colectiva?», Cuadernos de Derecho Transnacional, vol. 12, 2, 2020, pp. 1308-1309; A. MonTesinos García, «La propuesta de directiva para la tutela colectiva de los consumidores en la Unión Europea», Actualidad Civil, 9, 2018, pp. 1-3; F. CORDÓN Moreno, «Examen de los instrumentos de tutela previstos en la Directiva, del Parlamento y del Consejo, relativa a las acciones de representación para la tutela de los intereses colectivos de los consumidores», Revista CESCO de Derecho de Consumo, vol. 36, 2020; P. Gutiérrez de CABiedes, «Acciones colectivas: pretensiones y legitimación», en T. Armenta Deu, S. Pereira PuigVert (eds.) Acciones colectivas (cuestiones actuales y perspectivas de futuro), Marcial Pons, Madrid, 2018, pp. 44-46. 
mostrar el enorme impacto que dicho instrumento puede desplegar en materia de Derecho de consumo siguiendo el ejemplo estadounidense.

\section{El origen de la Directiva 2020/1828}

6. La aparición de nuevas fuentes de riesgo para consumidores y usuarios derivadas del desarrollo tecnológico se hace especialmente patente en el ámbito de la medicina satisfactiva, los medicamentos de consumo humano y los productos defectuosos ${ }^{15}$. Son de sobra conocidos los esfuerzos de la Comisión Europea ${ }^{16}$ por garantizar la protección de consumidores y usuarios en dichos ámbitos. Desde hace años son motivo de preocupación los daños y perjuicios debidos a incumplimientos tanto del Derecho de la competencia como de la normativa de consumo sufridos por dichos actores del mercado de la UE que han quedado sin compensación ${ }^{17}$.

7. Los escándalos más cercanos en el tiempo (Dieselgate e implantes defectuosos) ${ }^{18}$ y su dispar solución jurídica en los distintos ordenamientos de la $\mathrm{UE}^{19}$, han puesto de manifiesto la urgente necesidad de arbitrar un proceso colectivo europeo y de dotar de armas procesales más robustas a los damnificados ${ }^{20}$.

8. Es sabido que la asimetría informativa ${ }^{21}$ — punto clave cuando se impugnan pliegos de cláusulas contractuales, consentimientos informados y prospectos - entre los destinatarios de los productos y servicios y los profesionales, empresarios y fabricantes, así como el desigual coste de oportunidad proce$\mathrm{sa}^{22}$ hacen necesario un mecanismo similar a las class actions, mass torts y multidistrict litigation norteamericanas que incluya la exhibición de pruebas para tutelar adecuadamente a consumidores y usuarios ${ }^{23}$.

${ }^{15}$ Cfr. J. Muro Insausti, «Responsabilidad civil por productos defectuosos», en Aranzadi responsabilidad civil: doctrina, jurisprudencia, régimen legal y formularios, vol. III, Thomson Reuters, Aranzadi, Cizur Menor, 2012, pp. 426-432; M. Á. PARRA LuCÁn, «Responsabilidad civil por bienes o servicios defectuosos», en Rodrigo Bercovitz Rodríguez-Cano (ed.) Comentario del Texto Refundido de la Ley General para la Defensa de Consumidores y Usuarios y otras leyes complementarios (Real Decreto Legislativo 1/2007), 2, Thomson Reuters, Aranzadi, Cizur Menor, 2015, pp. 1843-2126.

${ }^{16}$ Comisión Europea, Libro Verde. Reparación de daños y perjuicios por incumplimiento de las normas comunitarias de defensa de la competencia, Bruselas, 2005; Libro Blanco. Acciones de daños y perjuicios por incumplimiento de las normas comunitarias de defensa de la competencia, Bruselas, 2008.

${ }^{17}$ Cfr. Considerandos 1-2 de la Directiva 2020/1828.

${ }^{18} \mathrm{~S}$. COROMINAS BACH, "El nuevo modelo alemán de acción declarativa (MFKG): ¿una tutela colectiva efectiva del Dieselgate?”, cit., pp. 2-4; A. HALfMEIER, Y P. RоTт, «Verbandsklage mit Zähnen? - Zum Vorschlag einer Richtlinie über Verbandsklagen zum Schutz der Kollektivinteressen der Verbraucher», Verbraucher und Recht, 2018, p. 244; M. HEESE, «Sachaufklärung im Dieselskandal — Probleme und Abhilfe», Neue Juristische Wochenschrift, vol. 13, 2021, pp. 891-893; A. STADLER, «Kollektiver Rechtsschutz quo vadis?», Juristen Zeitung, vol. 73, 17, 2018, sec. 793-794; UNSELD, C., «Grenzenloser Versicherungsschutz im Produkthaftungsrecht? Der Brustimplantate-Skandal erreicht zum zweiten Mal den EuGH (Rs. C- 581/18)», Europäische Zeitschrift für Wirtschaftsrecht, 2020. STJUE C-219/15 - Elisabeth Schmitt v. TÜV Rheinland LGA Products GmbH.

${ }^{19}$ En España, la reciente SJM Madrid 25 de enero de 2021 (RJ 4/2021).

${ }^{20}$ Considerando 5 de la Directiva 2020/1828.

${ }^{21}$ F. Díez Estella y M. De Prada Rodríguez, «Acciones de reclamaciones de daños derivados de ilícitos antitrust: principales problemáticas sustantivas y procesales», Aranzadi doctrinal, 2, 2019, p. 31. En idéntico sentido, la Comisión Europea: "en gran parte [a causa de] diversos obstáculos legales y procesales derivados de las normativas nacionales [...] las indemnizaciones por daños en este campo presentan una serie de características particulares que a menudo las normas procesales tradicionales y de responsabilidad civil abordan de manera insuficiente. Esto da lugar a una gran inseguridad jurídica. Entre las particularidades se incluyen [...] la frecuente inaccesibilidad y ocultación de pruebas cruciales por parte de los demandados y el equilibrio generalmente desfavorable entre el riesgo y la recompensa para los demandantes", Libro Blanco. Acciones de daños y perjuicios por incumplimiento de las normas comunitarias de defensa de la competencia, Bruselas, 2008, p. 2.

${ }^{22}$ Pues, en multitud de ocasiones, la cuantía del daño individual a recuperar es menor al coste del proceso. Cfr. Comisión Europea, Libro Verde. Reparación de daños y perjuicios por incumplimiento de las normas comunitarias de defensa de la competencia, cit., sec. 2.6; Libro Blanco. Acciones de daños y perjuicios por incumplimiento de las normas comunitarias de defensa de la competencia, cit., sec. 2.8; C. Meller-Hannich, «Sammelklagen, Gruppenklagen, Verbandsklagen - bedarf es neuer Instrumente des kollektiven Rechtsschutzes im Zivilprozess», Neue Juristische Wochenschrift - Beilage, 2018, pp. 31-32.

${ }^{23}$ A. StadLer, «Die Umsetzung der Kommissionsempfehlung zum kollektiven Rechtsschutz», Zeitschrift für die gesamte Privatrechtswissenschaft, 2015, pp. 61-84. 
9. Con toda claridad lo señala el Prof. GASCón INCHAusti: "Un elemento que caracteriza en gran medida los litigios en materia de consumo, incluidos los colectivos, es que una parte importante de las pruebas se halla en poder del empresario demandado o de terceros. El acceso a las fuentes de prueba relevantes es una premisa sin la que las entidades habilitadas no podrán ejercer las facultades que se les reconocen: se arriesgan a tener que asumir los costes de un proceso abocado al fracaso si no existe suficiente apoyo probatorio." ${ }^{24}$

10. Así, se comprende que la norma europea haya sido recibida, con alguna excepción ${ }^{25}$, muy positivamente ${ }^{26}$ y que las limitaciones que establece - la restricción de la legitimación activa a entidades habilitadas suficientemente representativas ${ }^{27}$ y la voluntariedad de numerosos de sus artículoshayan sido tan fuertemente criticadas $^{28}$. Destacados autores achacan este debilitamiento al lobby de la poderosa industria que se vería directamente afectada por las demandas ${ }^{29}$.

\section{La efectividad del discovery estadounidense a la luz de la jurisprudencia sobre productos de- fectuosos}

11. Si adoptamos una perspectiva comparada más amplia y contemplamos la disparidad de resoluciones en materia de Derecho de daños entre EE. UU., España y Alemania que se deben a la inexistencia de discovery en los países del viejo continente, la necesidad y urgencia de establecer un generoso modelo de exhibición de pruebas se hace aún más clara. Veámoslo con varios ejemplos.

\section{Anticonceptivos hormonales de tercera generación (Drospirenona / ethynilstradiol)}

12. Desde su autorización en el año 2000 por la Agencia Europea del Medicamento y un año más tarde en EE. UU. por la FDA, los anticonceptivos hormonales con drospirenona son uno de los métodos anticonceptivos más extendidos en ambos mercados ${ }^{30}$.

24 “¿Hacia un modelo europeo de tutela colectiva?”, cit., p. 1312. En idéntico sentido, A. Montesinos García, “La propuesta de directiva para la tutela colectiva de los consumidores en la Unión Europea”, cit., p. 5: «Al respecto, las entidades habilitadas podrán solicitar al órgano jurisdiccional que el comerciante demandado facilite las pruebas pertinentes para su reclamación o necesarias para informar adecuadamente a los consumidores afectados por la acción de representación, tales como la identidad de los consumidores afectados y la duración de la práctica. Este deber de colaboración del demandado puede llegar a resultar sumamente útil en determinados procesos colectivos en los que la obtención de la prueba por parte del demandante puede resultar diabólica, mientras que para el demandante, mostrar ninguna complejidad.».

${ }^{25}$ A. BRuns, «Instrumentalisierung des Zivilprozesses im Kollektivinteresse durch Gruppenklagen?», Neue Juristische Wochenschrift, 2018, pp. 2753-2757. La escepticismo mostrado por el Prof. Alfaro REAL en nuestro país, se refiere a las acciones en materia de ilícitos anticoncurrenciales. Aqueja el autor una falta de persecución pública de tales infracciones en materia de competencia. Dicha crítica no es trasladable a las acciones de consumidores y usuarios en las que dicha vigilancia por parte de la Comisión no existe. Cfr. J. Alfaro ÁGuila-Real, «Contra la armonización positiva: la Propuesta de la Comisión para reforzar el private enforcement del Derecho de la Competencia», InDret, 3, 2009, pp. 20-30.

${ }^{26}$ H. PRÜTtING, «Neue Entwicklungen im Bereich des kollektiven Rechtsschutzes», Zeitschrift für Wirtschaftsrecht, 2020, pp. 202-203; A. STADLER, “Kollektiver Rechtsschutz quo vadis?”, cit., pp. 801-803; M. TAMm, «§ 24 b Die Musterfestellungsklage», en M. TAMm, K. TONNER, T. BRÖNNEKE (eds.) Verbraucherrecht. Rechtliches Umfeld $\mid$ Vertragstypen $\mid$ Rechtsdurchsetzung, 3, Nomos, Baden - Baden, 2020, nn. 22-25.

${ }^{27}$ Gascón Inchausti, F., “¿Hacia un modelo europeo de tutela colectiva?”, cit., pp. 1299-1306.

${ }^{28}$ T. DomEJ, «Die geplante EU-Verbandsklagenrichtlinie - Sisyphos vor dem Gipfelsieg?», Zeitschrift für Europäisches Privatrecht, 2019, 469-471; A. Montesinos García, "La propuesta de directiva para la tutela colectiva de los consumidores en la Unión Europea", cit., p. 6.

${ }^{29}$ A. HALFMEIER Y OTROS, "Verbandsklage mit Zähnen? - Zum Vorschlag einer Richtlinie über Verbandsklagen zum Schutz der Kollektivinteressen der Verbraucher", cit., p. 244; P. RöTHEMEYER, «Deutsche Rechtspolitik zwischen Lobbyismus und Dieselgate», en P. RötHEMEYER (ed.) Musterfeststellungsklage. Spezialkommentar zum 6. Buch ZPO, 2, Nomos, Baden - Baden, 2020, nn. 90-102.

${ }^{30}$ K. Daniels y J. C. ABMA, «Current Contraceptive Status Among Women Aged 15-49: United States, 2015-2017», National Center for Health Statistics. Data Brief, vol. 327, 12, 2018; European Parliamentary Forum for Sexual \& Reproductive Rights, European Contraception Policy Atlas 2020, Brussels, 2020; B. KueHn, «US Contraceptive Use. News From the Centers for Disease Control and Prevention», JAMA, vol. 321, 8, 2019; M. Llamas y E. MilleR y S. SPENCE, «Yaz Birth Control: Uses, Dosages, Interactions and Warnings», Drugwatch, 17.3.2021, https://www.drugwatch.com/yaz/, fecha de consulta 8 julio 2021. 
En España, los preparados hormonales son el segundo más utilizado ${ }^{31}$.

13. El impacto en la salud de estos productos tiende a ser muy similar en los distintos países. Esto es, los efectos adversos que provocan no dependen de la jurisdicción en la que se produzcan los daños. Por ese motivo, analizar de forma comparada la dispar fortuna procesal de las acciones entabladas para exigir la compensación por daños y perjuicios derivados de productos defectuosos ayuda a mostrar las deficiencias y aciertos de los instrumentos procesales al alcance de los consumidores y usuarios afectados.

14. En consecuencia, se procede a hacer un repaso de los pronunciamientos judiciales habidos en EE. UU., Alemania, Suiza y España con ocasión de los mencionados contraceptivos.

\section{A) In re Yasmin \& Yaz (Drospirenone) Marketing, Sales Practices \& Products Liability Litigation, 655 F. Supp. $2 d 1343$ (2009)}

15. En 2009 se inició en EE.UU. una Mass Torts $^{32}$ que aunaba más de 19.000 demandas $^{33}$ de mujeres consumidoras de Yaz, Yasmin, Ocella y marcas asociadas. La corporación farmacéutica demandada fue el grupo Bayer, Schering y Berlex. Tras diez años de proceso en la Corte de Litigación Multidistrito de Illinois del Sur, el resultado ha sido una astronómica transacción judicial de 2.100 millones de dólares en compensación por los daños sufridos por todas las consumidoras perjudicadas ${ }^{34}$.

16. Pues bien, el informe pericial del Dr. Kessler ${ }^{35}$ (antiguo presidente de la Food and Drug Administration), que resultó decisivo para los demandantes, fue posible gracias al extenso y profundo discovery — más de dos años de investigaciones, multitud de interrogatorios, revisión de comunicaciones internas, estudio de los flujos financieros de las empresas farmacéuticas...- que la normativa americana permite ${ }^{36}$. De esta forma pudo destaparse: i) el entramado de estudios maquillados que rebajaban la prevalencia de distintos efectos adversos de los anticonceptivos comercializados, ii) la financiación camuflada de dichos estudios poblacionales llevados a cabo por la corporación farmacéutica alemana a través de terceros interpuestos para hacerlos parecer independientes y iii) la promoción del producto para fines distintos a los de la aprobación ${ }^{37}$.

\section{B) LG Waldshut-Tiengen, Urt. v. 20. 12. 2018 - 10 73/12}

17. Por lo que se refiere a Alemania — donde también se ha informado de numerosos casos de consumidoras afectadas $^{38}$ — en el único supuesto que ha llegado a los tribunales, la demandante — que

\footnotetext{
${ }^{31}$ Sociedad Española de Contracepción, «Utilización y edad», en Encuesta Nacional 2018 sobre la Anticoncepción en España, SEC, Madrid, 2019.

${ }^{32}$ «In re Yasmin \& Yaz (Drospirenone) Marketing, Sales Practices \& Products Liability Litigation, 655 F. Supp. 2 d 1343 (2009)|Caselaw Access Project», fecha de consulta 8 julio 2021, en https://cite.case.law/f-supp-2d/655/1343/. Caso muy similar es el del anillo hormonal anticonceptivo NuvaRing de la compañía Merck. Cfr. In re Nuvaring Products Liability Litigation, 572 F. Supp. $2 d 1382$ (2008).

${ }^{33}$ El número notificado de mujeres fallecidas a causa del consumo de dicho preparado hormonal asciende a 853 en EEUU y 19 en Alemania. Cfr. www.risiko-pille.de

${ }^{34}$ M. Llamas y E. Miller, «Yaz Lawsuits | Blood Clot, Heart Attack \& Stroke Claims», Drugwatch, 17.3.2021, fecha de consulta 8 julio 2021, en https://www.drugwatch.com/yaz/lawsuits/.

${ }^{35}$ D. A. Kessler, «Expert Report. David A. Kessler, M.D. Filed under Seal. Exhibit A». El resto de informes periciales llegaron a conclusiones similares, cfr. J. D. ABRAMSON, «Expert report. In re: YASMIN, YAZ Products Liability Litigation»; C. D. BlumE, «Expert Report. Thrombotic/thromboembolic events associated with drospirenone-containing oral contraceptives»; Gerstman, B. B., «The risk of Drospirenone-associated venous thromboembolism»; C. T. STIER, «Report on Drospirenone containing Combined Oral Contraceptives (COCs)».

${ }^{36}$ Sobre el Discovery-plan, cfr. Committe on the Judiciary House of Representatives, "Federal Rules of Civil Procedure", cit. Rule 26 (f) (3).

${ }^{37}$ D. A. KessLer, “Expert Report. David A. Kessler, M.D. Filed under Seal. Exhibit A”, cit., pp. 3-33, 36-42, 119-122.

${ }^{38}$ De nuevo cfr. www.risiko-pille.de
} 
había sufrido un infarto cerebral y fue resucitada tras siete minutos de muerte encefálica - fue condenada al pago de las costas judiciales por no poder despejar la posibilidad — tal como exige el $\S 84.2$ $A M G$ - de que el tromboembolismo padecido no se debiera al vuelo transoceánico que realizó cuatro meses antes del ataque ${ }^{39}$.

18. La única información que le fue facilitada a la demandante cuando adquirió el producto era de tipo comercial - los tres efectos beneficiosos del contraceptivo que el informe Kessler demostró exagerados o directamente falsos- - y no recogía las contraindicaciones que todo prospecto ha de contemplar. El juzgador de instancia entendió que la exigencia de información que establece la $A M G$ no se aplicaba a dicho folleto por tratarse de un documento dirigido al marketing del producto.

19. La Corte de apelación de Karlsruhe confirmó la desestimación de la demanda por idénticos $\operatorname{motivos}^{40}$.

\section{C) Bundesgericht I. zivilrechtliche Abteilung, Urteil vom 5. Januar 2015}

20. A un resultado similar (condena en costas judiciales a la demandante por valor de 174 mil francos) llegó el famoso caso suizo de Céline ${ }^{41}$. En dicho proceso, no sólo carecía la demandante de instrumentos similares al discovery para demostrar la estrategia de ocultamiento de los efectos adversos del fármaco, sino que el Tribunal expresamente rechazó tomar en consideración el referido "informe Kessler" ${ }^{\prime 2}$. En las tres instancias se confirmó la desestimación de la reclamación presentada.

\section{D) Los casos habidos en España}

21. Sorprendentemente en nuestro país no ha habido demandas por los daños sufridos por las mujeres afectadas por esta saga de anticonceptivos hormonales con Drospirenona. La AEMPS, sin embargo, ha informado de numerosos casos (se han notificado 92 incidencias directamente relacionadas con los mencionados contraceptivos) $)^{43}$ de usuarias afectadas por las distintas marcas de estos preparados hormonales.

22. Resulta comprensible el recelo de los despachos de abogados en España a iniciar demandas careciendo de los medios procesales clave para exigir a la parte demandada las fuentes de prueba en las que sustentar los informes periciales que demuestren la relación de causalidad entre los padecimientos y el consumo de los fármacos; así como el ocultamiento de los efectos adversos en los distintos estudios financiados por las propias compañías.

\section{Otros supuestos}

23. Los ejemplos de soluciones dispares debidas a una insuficiente prueba que a su vez trae

${ }^{39}$ LG Waldshut-Tiengen, Urt. v. 20. 12. 2018 - 1 O 73/12. Cfr. D. FranzKi y A. Spickhoff, «Ausschluss der Kausalitätsvermutung (AMG $\S 84$ Abs. 2 S. 3)», en B. Gsell, W. Krüger, S. Lorenz, C. Reymann, A. Spickhoff (eds.) Grosskommentar zum Zivilrecht, C. H. Beck, München, 2020, pp. 111-112.2; RedAKTION, «Zur Haftung nach § 84 Abs. 2 AMG (Antibabypille «Yasminelle»)», Pharma Recht - Fachzeitschrift für das gesamte Arzneimittelrecht, 2019, pp. 75-82.

${ }^{40}$ OLG Karlsruhe Urt. v. 25.06.2021, Az. 4 U 19/19.

${ }^{41}$ Tras apenas una semana de consumo de las píldoras anticonceptivas sufrió un repentino tromboembolismo, seguido de un infarto cerebral y hoy padece importantes secuelas debidas a los daños encefálicos padecidos. Cfr. C. PfLeger HürLIMANN, "Céline» Antibabypille - und plötzlich schwerstbehindert, 2, Schild, Elbingen, 2017.

${ }^{42}$ Bezirksgerichtes Zürich 8. Abteilung, Urteil vom 13. August 2013 (CG090220-L); Obergericht des Kantons Zürich I. Zivilkammer, Beschluss und Urteil vom 7. Mai 2014; Bundesgericht I. zivilrechtliche Abteilung, Urteil vom 5. Januar 2015.

${ }^{43}$ M. J. Lamas Díaz, Expediente 001-049279 de 4 de diciembre, Madrid, 2020, p. 4. 
causa de la carencia de medios procesales que posibiliten una investigación profunda podrían multiplicarse $^{44}$ y no sólo en el ámbito de los productos farmacéuticos ${ }^{45}$.

24. Actualmente está abierto un nuevo proceso contra la empresa Bayer por el anticonceptivo mecánico Essure que ha provocado numerosas lesiones y muertes en todos los países donde se ha comercializado ${ }^{46}$. Recientemente ha podido conocerse que la corporación farmacéutica planea un desembolso de 1,6 mil millones de dólares para las transaccionar en torno al $90 \%$ de las más de 39.000 demandas a las que la compañía se enfrenta en los tribunales de EE. UU. ${ }^{47}$.

25. A raíz de sucesos como éste, la legislación sanitaria americana (Obamacare) ha obligado a las compañías farmacéuticas a publicar los datos financieros sobre los pagos realizados a médicos y de esta manera sacar a la luz los innumerables conflictos de intereses de quienes prescriben los medicamentos, han de informar rigurosamente a los pacientes de los riesgos asociados a su ingesta y simultáneamente se ven económicamente beneficiados por aconsejar o vender directamente tales productos. La información puesta a disposición del público, a través de la plataforma Propublica Data Store, ha dado lugar a portales que facilitan la búsqueda en dicha base de datos como Dollarsfordocs. En ésta última se muestran, entre otros, con toda claridad los pagos realizados por Bayer a los ginecólogos americanos que resultaron ser los más decididamente promotores del dispositivo Essure ${ }^{48}$.

26. En España, este dispositivo también ha dejado numerosas víctimas, en torno a 3.500 personas. Cifra nada desdeñable sabiendo que se han implantado unos 80 mil dispositivos desde 2002 en nuestro país ${ }^{49}$. La plataforma AfectadasEssure interpuso una querella criminal contra la mencionada

\footnotetext{
${ }^{44}$ Con la excepción del “caso Agreal” (STS 10 de julio de 2014 (RJ 2014\4318) MP: José Antonio Seijas Quintana) —en cuyos pronunciamientos cabe observar una evidente falta de medios probatorios que demuestren la relación de causalidad entre el fármaco y la depresión padecida por las consumidoras afectadas - las desestimaciones son la regla general. Así con los fármacos: Zyprexa, VIOXX, Nolotil, Levothroid... Especialmente grave es el caso del fármaco VIOXX (In re Vioxx Products Liability Litigation, 230 F.R.D. 470 (2005)) que en EEUU terminó con la vida de más de 60.000 pacientes. La compañía Merck había ocultado a la FDA estadounidense los estudios epidemiológicos que revelaban los efectos adversos del fármaco. En consecuencia, debió pagar en torno a 850 millones de dólares para saldar su responsabilidad penal en la causa criminal abierta contra ella y 4,85 mil millones en daños y perjuicios a los damnificados y sus familias. Es clamoroso que en nuestro país el proceso terminara con una desestimación en primera instancia (SAP Madrid 4 de mayo de 2011 (RJ 6538/2011) y en Alemania con una desestimación por el Tribunal Supremo (BGH, Urteil vom 26. 03. 2013 - VI ZR 109/12). Cfr. K. ComPTON y K. Connolly y A. Gerberich, «Vioxx», Drugwatch, 26.6.2020, fecha de consulta 8 julio 2021, en https://www.drugwatch. com/vioxx/. P. SALVADOR Coderch y Otros, «150 casos de derecho de daños (2004-2014)», InDret, 4, 2015, Barcelona, pp. 2829. J. Muro Insausti, "Productos defectuosos", cit., pp. 426-432. D. FranzKi y T. Vogel, «Grenzen der Kausalitätsvermutung und des Auskunftsanspruchs im Arzneimittelhaftungsrecht», Neue Juristische Wochenschrift, 2013, pp. 2862-2865; REDAKTION, «BGH: Schadenseignung in $\S 84$ II 3 AMG ebenso auszulegen wie in $\S 84$ II 1 AMG», Pharma Recht - Fachzeitschrift für das gesamte Arzneimittelrecht, 2013.

${ }^{45}$ Es conocida la condena de Philipp Morris, en EEUU, por no avisar de los riesgos conocidos y ocultados a los consumidores de tabaco y la absolución de Tabacalera en España (STS de 4 de marzo de 2009 (RJ 1132/2009). MP: Juan Antonio Xiol Ríos; SAP Girona 11 de abril de 2005 (RJ 595/2005); SAP Barcelona de 1 de diciembre de 2003 (RJ 7224/2003). Del mismo modo ha ocurrido con la desestimación de las reclamaciones derivadas de los daños derivados de distintas intervenciones de medicina satisfactiva: fotodepilación láser, cirugía LASIK de reparación ocular e implantes mamarios defectuosos... De nuevo, cfr. F. J. Muro InSAusti, «Productos defectuosos», en Francisco Javier Muro Insausti (ed.) Aranzadi responsabilidad civil: doctrina, jurisprudencia, régimen legal y formularios, vol. III, Thomson Reuters, Aranzadi, Cizur Menor, 2012.

${ }^{46}$ Bertelsman, W. O. y United States District Court for The Eastern District of Kentucky Covington Division, Amy Lynn Coghill vs. Bayer Corporation, et al. Civil Action n. 2:19-cv-158-WOB-CJS, 2020. Bailey, Rene Leach et al. v. Bayer Corporation, et al., 2020.; Land, C. D. y U.S. District Court Judge Middle District of Georgia, Kimberly Frey vs. Bayer Corporation et al. Case No 3:20-CV-41 (CDL), 2020.; Rowland, M. M., Vivian Elrod v. Bayer Corporation et al. Case No. 19 cv $06048,2020$.

${ }^{47}$ M. Llamas y E. Miller y T. Schulman, «Essure Lawsuits», Drugwatch, 12.3.2021, fecha de consulta 8 de julio 2021, en https://www.drugwatch.com/essure/lawsuits/; RedAKTION BeCK-AKtuelL, «Bayer einigt sich in den USA mit Essure-Klägerinnen auf Milliardenvergleich», Beck-Aktuell. Nachrichten, Pressemitteilungen, Fachnews, 2020, München.

${ }^{48}$ M. Tigas y R. G. Jones y C. Ornstein y L. Groeger, «Dollars for DOCs», 2021, fecha de consulta 8 de julio 2021 en https://projects.propublica.org/docdollars/products/5896.

${ }^{49}$ La Asociación Libres de Essure España aúna a más de 2.400 afectadas. Cfr. S. Guardón, «La Plataforma Asociada Libres de Essure expone al CGCOM la situación de las afectadas por este anticonceptivo», Médicos y Pacientes, 2019, Madrid.
} 
compañía, la Sociedad Española de Ginecología y la Agencia Española del Medicamento ${ }^{50}$. Parece adivinarse que la vía procesal elegida (penal) se ha escogido precisamente por la amplitud de las diligencias previas. De nuevo, esta legítima estrategia no hace sino revelar las limitaciones del proceso civil español en lo referido a la exhibición de pruebas. Tratándose de reclamaciones por daños (contractuales, extracontractuales o con base en el TRLGDCU), el cauce natural es el proceso civil. El posterior archivo de la querella pone de manifiesto este extremo ${ }^{51}$.

27. A principios de octubre de 2020 se hizo público el acuerdo alcanzado por los representantes legales de la Plataforma Libres de Essure España (distinta a la anterior) con la compañía aseguradora del servicio público de salud ${ }^{52}$. Continua, sin embargo, el proceso de reclamación de daños contra la corporación farmacéutica Bayer por ser la productora y distribuidora del fármaco.

28. Una vez contemplado el panorama comparativo entre España, Alemania y EE. UU. con base en supuestos de responsabilidad civil con numerosos consumidores y usuarios afectados, procede estudiar con algo de detalle el instrumento de la exhibición de pruebas tal como se practica en EE. UU.

\section{US Civil Litigation and Discovery}

29. La exhibición de fuentes de prueba para la preparación de la vista oral —en la que se somete a contradicción la evidencia elaborada gracias a los elementos de convicción obtenidos- es quizás el elemento más característico del proceso civil norteamericano. La transparencia y colaboración que exige a las partes implicadas - y a terceros con información relevante para el caso- facilita enormemente la preparación del juicio oral (trial) pues, de lo contrario, muchos litigantes se verían obligados a emprender acciones "a ciegas". Esto es, estarían abocados a la desestimación de sus pretensiones por carecer de medios legales que les permitan corroborar - con evidencia que se encuentra en poder de la parte contraria o de terceros - los hechos que fundamentan sus alegaciones.

30. Así pues, el objetivo que persigue este instrumento es doble. En primer lugar, el conocimiento exacto de los hechos y la probabilidad de obtener el pronunciamiento judicial deseado. En segundo lugar, promover la transacción entre las partes a la luz de lo hallado en la investigación de las pruebas y evitar los costes del proceso completo.

31. Aunque la legislación procesal civil es competencia estatal, la mayoría de las jurisdicciones prevén un modelo de exhibición de pruebas similar que, a su vez, toma como referencia la legislación federal (Federal Rules of Civil Procedure) ) $^{33}$. En el ámbito del Derecho de daños (Torts Law) cuya regulación es competencia de los Estados federados ${ }^{54}$, las cortes encargadas del enjuiciamiento suelen ser las estatales (no las federales) porque - con algunas excepciones como el preemption - aplican Derecho estatal. Por este motivo y a los efectos que aquí interesan (diligencias de acceso a fuentes de prueba en el marco de la protección de consumidores y usuarios), se toma como referencia la normativa procesal

\footnotetext{
${ }^{50}$ N. Villanueva y J. G. Stegmann, «La Audiencia Nacional estudia una querella contra Bayer de treinta víctimas del anticonceptivo Essure», $A B C, 2018$, Madrid.

${ }^{51}$ M. PINHEIRO, «La Audiencia Nacional rechaza investigar el caso de las mujeres afectadas por el anticonceptivo Essure», elDiario.es, 2018, Madrid.

${ }^{52}$ Castreje \& Co Abogados, «Essure: acuerdo extrajudicial-aseguradora de servicio público de salud indemniza a afectada por determinados daños excepto los que tienen su origen en el producto defectuoso», 2020, fecha de consulta 8 julio 2021, en http://www.castrejeabogados.com/noticias/?p=1147; E. J. SALAZAR, «El drama que no cesa de las afectadas por el anticonceptivo de Bayer», elDiario.es, 2019, fecha de consulta 8 julio 2021, en https:/www.eldiario.es/comunitat-valenciana/alicante/ drama-cesa-afectadas-anticonceptivo-bayer_1_1393489.html.

${ }^{53}$ US Middle District of Florida Magistrate and District Judges, Middle District Discovery. A Handbook on civil discovery practice in the US District Court for the Middle Disctrict of Florida, Middle District of Florida, Fort Myers, Jacksonville, Ocala, Orlando and Tampa, 2015, p. 4.

${ }^{54}$ K. S. Abraham, The Forms and Functions of Tort Law, 4, Foundation Press, St. Paul, Minnesota, 2012, pp. 1-5.
} 
del Estado de California, cuyo desarrollo es particularmente intenso y porque el tratado sobre la materia más detallado y actualizado se refiere a la ley rituaria de dicho Estado ${ }^{55}$.

32. Pasamos pues a hacer un somero repaso de los elementos principales de este instrumento procesal.

\section{Discovery Plan}

33. Una vez presentada la demanda - que no ha de ser completa sino que basta con que sea plausible y contenga los elementos suficientes para delimitar los sujetos, los hechos básicos y las pretensiones - y superado el primer filtro del archivo de las actuaciones (motion to dismiss o motion for sumary judgment ${ }^{56}$ ), ambas partes han de colaborar poniendo a disposición del contrario la información que sea relevante para el caso que esté bajo su poder y dar noticia de la que obre en poder de terceros en un plazo de dos semanas.

34. A continuación, deberá el demandante, si lo estima oportuno, presentar un plan más exhaustivo exigiendo nuevos medios de prueba. En el que deberá figurar tanto el alcance de las pesquisas como el tiempo estimado para su realización. Por su parte, el demandado podrá pedir al juez la exclusión de alguna de las fuentes de prueba exigidas que encajen bajo las categorías expresamente previstas a través de una orden de protección (protective order).

\section{Tipos de fuentes de prueba (Discovery methods)}

35. Los tipos de fuentes de prueba que la legislación permite obtener son los siguientes:

\section{A) Declaraciones juradas orales (oral depositions)}

36. Se trata de un interrogatorio a una de las partes o bien a un tercero con información relevante dirigido por uno de los abogados actuantes. De ordinario, el abogado contrario también participa para asegurar que las preguntas guardan relación con el caso y para plantear las objeciones que entienda pertinentes. Ha de estar también presente un taquígrafo que tome cumplida cuenta del interrogatorio que, además, suele grabarse.

37. Estas declaraciones resultan de una importancia crucial para preparar los futuros interrogatorios en la vista oral y anticipar las preguntas de la parte contraria a los testigos presentados durante el cross-examination.

\section{B) Declaraciones juradas escritas (written depositions)}

38. De modo similar puede exigirse a una de las partes o a terceros mediante preguntas escritas que ellos deben responder oralmente y cuyas respuestas son consignadas por un estenógrafo. Se acude

\footnotetext{
${ }^{55}$ La exposición de este capítulo de basa fundamentalmente en DeMeo, J. N. y отros, California Deposition and Discovery Practice, cit., $\S \$ 1.01-1.06$. Entre los autores españoles que han trabajado la materia pueden consultarse inter alia, L. CARBALLO PIÑEIRO, «La actividad preparatoria de un litigio internacional: de las diligencias preliminares a la pre-trial discovery», La Ley, 5211, 2005; A. Larrañaga Ysasi-Ysasmendi Y L. García Del Río, «Las empresas españolas frente al discovery del proceso judicial americano», La Ley, 2536, 2007.

${ }^{56}$ Aunque de ordinario esta segunda motion suele presentarse una vez concluido el discovery para evitar el juicio oral.
} 
a este formato de declaración cuando el declarante se encuentra en otro Estado o bien no es posible la presencia de los abogados de las partes.

\section{C) Interrogatorios escritos a una de las partes (written interrogatories to a party)}

39. A diferencia del anterior, este tipo de diligencia puede dirigirse solo a alguna de las partes y se responde de forma escrita. En consecuencia, el interrogado tiene mucho más tiempo para preparar el contenido. Por ello, se utiliza para pedir información precisa sobre fechas, empleados, contratos, etc. que de forma espontánea el cuestionado no puede facilitar porque necesita recopilar la información solicitada.

\section{D) Inspección de documentos, cosas y lugares (inspections of documents, things, and places)}

40. Con toda probabilidad, esta diligencia es la de más amplio espectro y la que exige más trabajo de selección y búsqueda de la información relevante ${ }^{57}$. Esto es, el rango de posibles documentos (sean físicos o digitales) abarcados por este medio es enorme. Actualmente, tiene lugar en su mayoría de forma electrónica. Se trata del llamado e-discovery ${ }^{58}$. Para evitar tácticas obstruccionistas dilatorias como la puesta a disposición de ingentes cantidades de documentos irrelevantes o la práctica abusiva de las fishing expeditions (petición indiscriminada de documentos para hallar algún tipo de infracción y, a continuación, buscar potenciales clientes perjudicados) se ha ido moderando jurisprudencialmente el uso del e-discovery y se han desarrollado poderosas herramientas de búsqueda para agilizar esta tarea ${ }^{59}$.

\section{E) Exploración física y psicológica (physical and mental examinations)}

41. Consiste en el examen y reconocimiento por parte de un médico forense de una de las partes o bien - en casos debidamente justificados - de terceras personas. También incluye las pruebas de paternidad y las tendentes a identificar el grupo sanguíneo.

42. En la mayoría de supuestos de responsabilidad civil por daños personales el examen médico de las secuelas es de capital importancia para determinar el alcance del resarcimiento a sufragar.

\section{F) Petición de admisión de la veracidad de hechos y documentos (requests for admissions)}

43. A través de esta diligencia se solicita a la contraparte la admisión de la veracidad de hechos y documentos que se tendrán por auténticos durante el juicio. Tiene, por tanto, el valor de una admisión judicial. Como bien puede advertirse ayuda a fijar los presupuestos fácticos que no podrán ser impugnados de forma sorpresiva durante la vista oral.

${ }^{57}$ El hallazgo de los extremos que prueban los hechos alegados de forma incontestable y fundamentan el corazón de las pretensiones suele llamarse en la jerga jurídica haber encontrado: la pistola humeante (the smoking gun) o el documento mortífero (the killing document).

${ }^{58}$ B. Schaufenbuel, E-Discovery and the Federal Rules of Civil Procedure, IT Governance Publishing., Ely, 2007. En nuestro país el art. 336.5 LEC prevé un modelo de exhibición de prueba en parte similar pero mucho más limitado. Cfr. S. PUIG FAURA, «El acceso del perito informático-forense a fuentes de prueba en poder de terceros. Análisis del apartado $5 .^{\circ}$ del artículo 336 LEC tras la reforma de la LEC por la Ley 42/2015 de 5 de octubre», Diario La Ley, 8808, 2016.

${ }^{59}$ J. I. SOlAR CAYÓN, «La codificación predictiva para la realización de tareas de «e-discovery»», en José Ignacio Solar Cayón (ed.) La inteligencia artificial jurídica. El impacto de la innovación tecnológica en la práctica del Derecho y el mercado de los servicios jurídicos, Thomson Reuters, Aranzadi, Cizur Menor, 2019, pp. 145-169. 


\section{G) Intercambio recíproco de información sobre los peritos (simultaneous exchanges of expert trial witness information)}

44. Esta diligencia permite exigir a la contraparte la lista de peritos a usar en juicio, así como los datos sobre sus credenciales, el contenido principal de su informe y las fuentes utilizadas. A cambio el solicitante deberá permitir que el oponente tenga la misma información respecto de sus propios expertos.

\section{Bases de datos electrónicas (Public Access to Court Electronic Records)}

45. Otro de los instrumentos que más útil se revela en las class actions en las que los demandantes tienen representaciones legales distintas es la base de datos electrónica PACER (Public Access to Court Electronic Records). Aparte de servir para la presentación y notificación de documentos judiciales (la plataforma homóloga a LexNET), permite que otros abogados ${ }^{60}$ —incluso aunque no sean parte en el proceso, siempre que el escrito en cuestión no haya sido presentado under seal "bajo sello"61_ puedan acceder a todos los escritos presentados por las partes, las resoluciones del tribunal, los informes periciales, los interrogatorios escritos, las declaraciones juradas, etc.

46. Se posibilita de esta manera que otros abogados en un proceso similar (contra el mismo demandando e idénticos daños debidos al mismo producto o servicio) ante una jurisdicción distinta, puedan beneficiarse de los resultados obtenidos en un discovery llevado a cabo en otro Estado. O bien, que será el supuesto más frecuente, que los abogados de distintos grupos de afectados que demandan de forma conjunta se beneficien mutuamente de los hallazgos de sus respectivas pesquisas. La plataforma electrónica PACER beneficia igualmente a los representantes legales que demandan de forma sucesiva ante la misma corte que conoció del caso original cuyo proceso dio lugar al discovery. Este último supuesto nos lleva a la siguiente especialidad del proceso civil estadounidense: la litigación multidistrito.

\section{Litigación mulidistrito para agilizar el discovery (Multidistrict Litigation Statute, 28 U.S.C.A. $\S 1407)$}

47. Es experiencia común que en los supuestos de daños por productos y servicios defectuosos los damnificados se encuentren dispersos en distintas jurisdicciones. Una forma de facilitar la reclamación de tales daños es la creación de cortes federales multidistrito especializadas que absorben la competencia para llevar a cabo el discovery de distintos casos presentados ante diversas cortes federales ${ }^{62}$.

48. De esta manera, el tribunal en cuestión puede tener abierto un proceso contra un demandante durante años ${ }^{63}$. Es decir, se permite que distintos demandantes y grupos de demandantes puedan acudir a dicha corte en momentos distintos (no tienen que presentarse de forma simultánea ni bajo la misma representación procesal) y beneficiarse del discovery llevado a cabo por el comité de abogados demandantes (plaintiff's steering committee) seleccionado por el juez para dirigir la demanda en nombre de todos los litigantes.

\footnotetext{
${ }^{60}$ Dicha plataforma está incluso disponible para periodistas e investigadores. Esta transparencia exige la anonimización de muchos de los documentos (se eliminan referencias nominales, bancarias, direcciones, etc.).

${ }^{61}$ La presentación confidencial de dichos documentos no impide que pasado un plazo el juez pueda ordenar su desclasificación (unseal).

${ }^{62}$ D. F. Herr, Multidistrict Litigation Manual: Practice Before the Judicial Panel on Multidistrict Litigation, Thomson West, Eagan, Minnesota, 2020, cap. 3; R. H. Klonoff, Class Actions and Other Multi-Party Litigation, 4, West, Thomson Reuters, St. Paul, Minnesota, 2012, pp. 217-220.

${ }^{63}$ El caso In re Yasmin \& Yaz (Drospirenone) Marketing, Sales Practices \& Products Liability Litigation, 655 F. Supp. 2d 1343 (2009) acaba de darse por concluido en 2020, habiéndose iniciado en 2009.
} 
49. Adviértase que el discovery está diseñado para promover la transacción entre los litigantes y evitar el juicio. La gran mayoría de las demandas terminan en acuerdo. Por este motivo, resulta de tanta utilidad que los sucesivos demandantes en una litigación multidistrito puedan hacer uso de todo lo hallado por los anteriores ${ }^{64}$.

\section{Utilidad de la experiencia de litigación civil americana para el ordenamiento español}

50. Son muchas las cuestiones que una confrontación del modelo de litigación civil americano, basado en el discovery, provoca al compararlo con el español. Conociendo la inspiración de las Directivas 2014/104 y 2020/1828 en el modelo estadounidense - del que en algunos puntos ha querido expresamente distanciarse - parece obligado el análisis de nuestro ordenamiento procesal (actual en vigor y futuro) a la luz del Discovery norteamericano. En consecuencia, se ordenan las consideraciones en dos apartados: interpretación de lege lata y propuestas de lege ferenda.

\section{De lege lata: uso en un proceso español de pruebas obtenidas en un discovery americano}

51. Sabiendo que muchos de los casos de responsabilidad por infracción del Derecho de consumo se refieren a productos o servicios defectuosos que son idénticos (o muy similares) en España y en EE. UU., surge la pregunta de si podrán utilizarse en un proceso español los resultados (informes periciales, declaraciones juradas, interrogatorios, etc. obtenidos en un discovery americano ${ }^{65}$.

52. Pues bien, tanto la Ley de cooperación jurídica internacional (arts. 29-31) ${ }^{66}$ como la Convención de la Haya de $1970^{67}$ sobre obtención de prueba permiten esta posibilidad. En efecto, España ha formulado una reserva a dicha Convención para excluir la solicitud indiscriminada que los tribunales extranjeros pudieran exigir en el marco de un pre-trial discovery a las autoridades españolas. Ahora bien, tal limitación no aplica en sentido contrario (petición de tribunales españoles de documentos surgidos en un discovery extranjero) porque EE. UU. no ha formulado reserva alguna al Tratado. Esto es, como la norma española no exige reciprocidad (art. 3.2 LCJIMC) ${ }^{68}$, cabe utilizar en procesos españoles (igual sucede en Alemania) ${ }^{69}$ dichos resultados para elaborar la propia prueba.

53. Además, conociendo el tiempo que exigen las cartas rogatorias y sabiendo que cualquier persona (no necesita siquiera ser abogado) puede darse de alta en la plataforma PACER y consultar

${ }^{64} \mathrm{El}$ ahorro procesal (piénsese en el colapso de los tribunales por los casos de cláusulas suelo o en Alemania los derivados del Dieselgate) que dicho instrumento supone, hacen aún más atractiva esta figura. Cfr. P. GutiérRez DE CABIEDEs, "Acciones colectivas: pretensiones y legitimación", cit., pp. 40-41; M. HeESE, "Sachaufklärung im Dieselskandal — Probleme und Abhilfe", cit., nn. 33-35.

${ }^{65}$ Para el caso de un discovery llevado a cabo en un país miembro de la UE — actualmente sólo existe un instrumento similar en Irlanda (disclosure) y mucho más limitado- es de aplicación el Reglamento (UE) 2020/1783. Su art. 1 (define el ámbito de aplicación) no resuelve el problema interpretativo que suscitaba el anterior Reglamento 1206/2001. Cfr. G. ESTEBAN DE LA Rosa, «Prueba judicial y práctica del discovery en la Unión Europea», Revista Internacional de Doctrina y Jurisprudencia, vol. 5, 1, 2014, pp. 30-32.

${ }^{66}$ J. J. Forner i Delaygua, «De la práctica y obtención de pruebas», en F. P. Méndez GonzÁlez, G. Palao Moreno (eds.) Comentarios a la ley de cooperación jurídica internacional en materia civil, Tirant lo Blanch, Valencia, 2017, pp. 347-359.

${ }^{67}$ Hague Conference on Private International Law Permanent Bureau, Practical Handbook on the Operation of the Evidence Convention, 3, HCCH, The Hague, 2016, pp. 17-38; W. WumNest, «Das Haager Beweisaufnahmeübereinkommen (HBÜ)», en H.-G. Kamann, S. VölCKer, S. Ohlhoff (eds.) Kartellverfahren und Kartellprozess, 1, München, 2017, n. 112.

${ }^{68}$ A. Font i Segura, «Artículo 3. Principio general favorable de cooperación», en Fernando Pedro Méndez González, Guillermo Palao Moreno (eds.) Comentarios a la ley de cooperación jurídica internacional en materia civil, Tirant lo Blanch, Valencia, 2017, pp. 43-61.

${ }^{69}$ E. D. EsCHENFELDER, «Verwertbarkeit von Discovery-Ergebnissen in deutschen Zivilverfahren», Recht der internationalen Wirtschaft, 2006, pp. 443-449; E. D. EschENFELDER, «Möglichkeiten deutscher Unternehmen, US-amerikanische Discovery auch vor deutschen Gerichten zu nutzen», Praxis des Internationalen Privat- und Verfahrensrechts, 6, 2006, pp. 89-97. 
los documentos disponibles — muchos de ellos resultado del discovery—, surge una pregunta aún más interesante: $i$ se pueden utilizar tales documentos (informes periciales, interrogatorios, declaraciones juradas) que sean resultado de un discovery como prueba? Si versan sobre hechos que corroboran las alegaciones de quien los esgrime, la respuesta deberá ser afirmativa (también, en Alemania ${ }^{70}$ ). Se trata de la fuente oficial estadounidense que los propios litigantes americanos utilizan - recuérdese el funcionamiento de la litigación multidistrito y de las class actions - y el art. 281.1 LEC admite sin problema este medio de prueba.

\section{De lege ferenda}

54. El ámbito de aplicación de las diligencias de acceso a fuentes de prueba excluye expresamente el Derecho de consumidores y usuarios. Sin mucha explicación, el Ministerio de Justicia modificó la original Propuesta de Ley de la Sección Especial para la transposición de la Directiva 2014/104/UE, relativa a determinadas normas por las que se rigen las acciones por daños en virtud del Derecho nacional, por infracciones del Derecho de la competencia de los Estados miembros y de la Unión Europea. Recortó notablemente el ámbito original de aplicación ${ }^{71}$ de las diligencias de acceso a fuentes de prueba $^{72}$. La transposición de los arts. 18 y 19 de la Directiva 2020/1828 abren la posibilidad de replantear nuevamente el alcance de dichas diligencias.

\section{A) Amplias diligencias de acceso a fuentes de prueba para las demandas colectivas en defensa de consumidores y usuarios}

55. El legislador nacional deberá crear un mecanismo de exhibición de pruebas para las acciones en defensa de intereses colectivos de consumidores y usuarios. La posibilidad más sencilla sería simplemente extender las DAFP para incluir, también, este tipo de demandas.

56. Sin embargo, tal como la experiencia estadounidense muestra, una tutela integral de consumidores y usuarios exige un catálogo mucho más amplio que la exhibición de documentos. Conviene apuntar que las diligencias previstas en el art. 283 bis a) LEC no coinciden con los tipos de fuentes de prueba (discovery methods) habituales en EE. UU. Ni el ordenamiento español, ni tampoco el alemán ${ }^{73}$

\footnotetext{
${ }^{70}$ W. Wumnest, "Das Haager Beweisaufnahmeübereinkommen (HBÜ)”, cit., n. 120.

${ }^{71}$ Cfr. M. L. Escalada LóPEZ, «La propuesta de reforma de la LEC en materia de acceso a fuentes de prueba», Cuadernos de Derecho Transnacional, vol. 8, 1, 2016, pp. 160-165. Apartado contenido en C. Herrero SuÁrez, "La transposición de la directiva de daños antitrust. Reflexiones a raíz de la publicación de la propuesta de ley de transposición de la directiva", cit.; F. GASCÓN INCHAUSTI, "Aspectos procesales de las acciones de daños derivados de infracciones de las normas sobre defensa de la competencia: apuntes a la luz de la Directiva 2014/104 y de la propuesta de ley de transposición”, cit., pp. 141-143.

${ }^{72}$ F. CORdón Moreno, "La reclamación de daños por infracción del Derecho de la competencia. Innovaciones en materia probatoria y, en especial, la regulación del acceso a las fuentes de prueba", cit., p. 4; P. GonZÁlez Granda, "La regulación del acceso a las fuentes de prueba", cit., pp. 132-139.

${ }^{73}$ C. GRAVE, «§ 33g GWB Anspruch auf Herausgabe von Beweismitteln und Erteilung von Auskünften», en W. JAEGER, J. Kokott, P. Pohlmann, D. Schroeder (eds.) Frankfurter Kommentar zum Kartellrecht, 96, Otto Schmidt, Köln, 2020, nn. 1042; G. Mäsch, «§ 33g - Anspruch auf Herausgabe von Beweismitteln und Erteilung von Auskünften», en W. BERG, G. MäsCH (eds.) Deutsches und Europäisches Kartellrecht, 3, Luchterhand, München, 2018, n. 12; N. Preuss, «GWB § 33g Anspruch auf Herausgabe von Beweismitteln und Erteilung von Auskünften», en U. Loewenheim, K. M Meessen, A. RiesenKampfF, C. Kersting, J. Meyer-Lindemann (eds.) Kartellrecht. Kommentar zum Deutschen und Europäischen Rech, 4, C. H. Beck, München, 2020, nn. 4-10. Y tampoco son comparables las diligencias previstas en el §142 ZPO (referidas exclusivamente a la solicitud de documentos) con los discovery methods. Cfr. R. GREGER, «§ 142 ZPO Anordnung der Urkundenvorlegung», en R. ZöLLER (ed.) Zivilprozessordnung, 33, Otto Schmidt, Köln, 2020, nn. 1-17; T. LüPKE, ««Pre-Trial Discovery of Documents» und § 142 ZPOein trojanisches Pferd im neuen Zivilprozessrecht?», Insolvenzrecht, 2002, pp. 588-589; H. PRÜTTING, «§ 142 ZPO - Anordnung der Urkundenvorlegung», en H. PRÜtTing, M. Gerhlein (eds.) Zivilprozessordnung Kommentar, 12, Luchterhand, München, 2020, nn. 1-19; D. von Selle, «ZPO § 142 Anordnung der Urkundenvorlegung», en V. Vorwerk, C. Wolf (eds.) Beck'scher Online-Kommentar zum Zivilprozessordnung, 38, C.H. Beck, München, 2020, nn. 3-18. De igual forma, tampoco las diligencias previstas en las leyes especiales alemanas tienen el amplio alcance de las pesquisas permitidas a los litigantes en EEUU.
} 
- al transponer la Directiva 2014/104 - contemplan las declaraciones juradas, ni los interrogatorios escritos a una de las partes, ni la exploración física y psicológica, ni las peticiones de admisión de la veracidad de hechos, ni tampoco el intercambio recíproco de información sobre los peritos. Las DAFP se reducen únicamente a la inspección de documentos, cosas y lugares y la exigencia de solicitudes detalladas de los documentos relevantes parecen suponer que el consumidor conoce de antemano cuáles son. De hecho, su modesto alcance parece más bien una modificación de la diligencia preliminar de exhibición de cosa (art. 254.1.2 LEC), cuya interpretación jurisprudencial ya había ido ampliando la figura para incluir todo tipo de documentos ${ }^{74}$.

57. En efecto, la desproporción entre la información a disposición del consumidor dañado (en tantas ocasiones diseñada con fines comerciales por la propia compañía causante de los daños) y la que obra en poder del empresario prestador de servicios, del fabricante o del distribuidor es abismal. Por desgracia, tampoco los controles administrativos de calidad de productos y servicios son suficientes. De nuevo, tal como demuestran los casos de responsabilidad por productos farmacéuticos defectuosos, las propias Agencias de control (FDA, AEMPS y AEM) fueron sorteadas por las corporaciones en los procedimientos de aprobación de los medicamentos y en los procesos posteriores de farmacovigilancia. Es ilusorio pensar que con los instrumentos procesales actuales el consumidor ordinario que $v$. gr. acude a una farmacia y recibe un prospecto falseado esté en condiciones de impugnar la información que allí encuentra y desmontar la estrategia comercial de ocultamiento de riesgos a través estudios epidemiológicos maquillados. ¿Qué paciente puede financiar un estudio poblacional con una muestra suficientemente representativa que demuestre una mayor prevalencia de las distintas contraindicaciones de un fármaco de la que aparece en el prospecto?

58. Dejar desarmados a los destinatarios últimos de los productos y servicios — quienes sufren los daños - al negarles instrumentos procesales lo suficientemente potentes para combatir este tipo de estrategias corporativas es sencillamente anular la tutela judicial efectiva (art. 24.1 CE). Este derecho fundamental ha de conectarse con la obligada cooperación con los tribunales (118 CE), tal como exige la reiterada doctrina del TC:

"Así: (i) la STC 7/1994, de 17 de enero, FJ 6, [...] «Como hemos declarado en la STC 227/1991, fundamento jurídico 5 , cuando las fuentes de prueba se encuentran en poder de una de las partes del litigio, la obligación constitucional de colaborar con los tribunales en el curso del proceso (art. 118 C.E.) conlleva que dicha parte es quien debe aportar los datos requeridos, a fin de que el órgano judicial pueda descubrir la verdad. Asimismo, nuestra jurisprudencia afirma que los tribunales no pueden exigir de ninguna de las partes una prueba imposible o diabólica, so pena de causarle indefensión contraria al art. 24.1 CE, por no poder justificar procesalmente sus derechos e intereses legítimos mediante el ejercicio de los medios probatorios pertinentes para su defensa (SSTC 98/1987, fundamento jurídico 3, y 14/1992, fundamento jurídico 2). Sin que los obstáculos y dificultades puestos por la parte que tiene en su mano acreditar los hechos determinantes del litigio, sin causa que lo justifique, puedan repercutir en perjuicio de la contraparte, porque a nadie es lícito beneficiarse de la propia torpeza (STC 227/1991, fundamento jurídico 3$) »$.

$[\ldots]$

(i) Cuando se pueda hablar de imposibilidad material y no de negativa injustificada de la administración a la entrega del medio de prueba. Así, en la STC 140/1994, de 9 de mayo, FJ 4 b) se dijo que «ha de tenerse en cuenta que cuando las fuentes de prueba se encuentran en poder de una de las partes en el litigio, la obligación constitucional de colaborar con los órganos jurisdiccionales en el curso del proceso (art. 118 C.E.) conlleva que sea aquella quien deba acreditar los hechos determinantes de la litis (SSTC 227/1991). [...]; si bien las deficiencias y carencias en el funcionamiento de un órgano administrativo no pueden repercutir en perjuicio del solicitante de amparo, es claro que no nos encontramos ante un

Cfr. P. GotTwald, «§ 10 Internationales Beweisrecht», en H. Nagel, P. GotTwald (eds.) Internationales Zivilprozessrecht, 8, Otto Schmidt, Köln, 2020, nn. 10.39-10.42.

${ }^{74}$ R. Castrillo Santamaría, La preparación del proceso civil: las diligencias preliminares, Bosch, Barcelona, 2018, pp. 167-174, 459-465. 
supuesto [donde] no lo lleva a cabo invocando dificultades derivadas de deficiencia o carencias internas, como en el caso objeto de la STC 227/1991, sino ante el supuesto de una imposibilidad de proceder a esa acreditación ni aun tratando de reconstruir el expediente»"”75.

59. En efecto, como atinadamente señala el TC, cuando las fuentes de prueba se encuentran en poder de la contraparte, la tutela judicial efectiva en su vertiente de interdicción de la indefensión (art. 24.1 in fine CE) en conexión con el deber de cooperar con los tribunales ex art. 118 CE obliga al legislador a establecer mecanismos procesales eficaces para que puedan obtenerse las debidas reparaciones de los daños sufridos. Que el derecho a utilizar los medios de prueba pertinentes (art. 24.2 CE) sea un derecho de configuración legal (STC 1/1996 FJ 2), necesitado de una importante intervención del legislador para ser operativo, implica que podemos encontrarnos ante una inconstitucionalidad por omisión ${ }^{76}$. Es decir, la falta de previsión legal de diligencias de acceso a fuentes de prueba y la debilidad de los mecanismos afines existentes (diligencias preliminares, diligencias de comprobación de hechos, prueba anticipada, etc.) provoca auténtica indefensión y determina la imperativa necesidad de interpositio legislatoris ${ }^{77}$.

\section{B) Bases de datos electrónicas para la litigación nacional y transfronteriza}

60. Como una misma infracción del Derecho de consumo puede causar daños en distintos países de la UE, la Directiva contempla también la obligación de establecer acciones de representación transfronterizas ${ }^{78}$ en defensa de intereses colectivos de consumidores y usuarios ${ }^{79}$ (art. 6) y acciones de representación nacionales que puedan agrupar a consumidores y usuarios de distintos Estados y que se puedan dirigir contra un empresario domiciliado en lugar distinto al del país en el que la entidad habilitada esté registrada.

61. A ello debemos añadir que el artículo 14 establece que los Estados podrán — se trata de una disposición facultativa - crear bases de datos electrónicas accesibles al público. Así lo explica el Considerando 63:

"Los Estados miembros deben poder crear bases de datos electrónicas nacionales, de acceso público a través de sitios web que proporcionen información sobre las entidades habilitadas designadas con antelación para ejercitar acciones de representación nacionales y transfronterizas, así como información general sobre las acciones de representación en curso y concluidas".

${ }^{75}$ STC 165/2020, FJ 4. Cfr. J. Garberí Llobregat, «Artículo 118 CE», en M. Rodríguez-Piñero y Bravo-Ferrer, M. E. CaSas BaAmonde (eds.) Comentarios a la Constitución Española: XL aniversario, vol. II, 2, Fundación Wolters Kluwer, Boletín Oficial del Estado, Tribunal Constitucional y Ministerio de Justicia, Madrid, 2018, pp. 676-677.

${ }^{76}$ STC 159/2011 FJ 5: "respecto a la inconstitucionalidad por omisión este Tribunal "ha declarado que la misma sólo se produce cuando la propia Constitución 'impone al legislador la necesidad de dictar normas de desarrollo constitucional y el legislador no lo hace' (SSTC 24/1982, FJ 3; y 74/1987, FJ 4)” (STC 87/1989, de 11 de mayo, FJ 2).”

${ }^{77}$ La mencionada insuficiencia legislativa ha sido reiteradamente denunciada por la doctrina. Por todos, P. GUTIÉRREZ DE CABIEDES, “Acciones colectivas: pretensiones y legitimación”, cit., pp. 17-23.

${ }^{78}$ Sobre el concepto y su alcance, cfr. T. DOMEJ, "Die geplante EU-Verbandsklagenrichtlinie - Sisyphos vor dem Gipfelsieg?", cit. P. 425; C. UNSELD, “Grenzenloser Versicherungsschutz im Produkthaftungsrecht? Der Brustimplantate-Skandal erreicht zum zweiten Mal den EuGH (Rs. C- 581/18)", cit., pp. 460-463.

${ }^{79}$ Así las define el Considerando 23 por oposición a las acciones nacionales: "Cuando una entidad habilitada ejercite una acción de representación en un Estado miembro distinto de aquel en el que haya sido designada, dicha acción debe considerarse una acción de representación transfronteriza. Cuando una entidad habilitada ejercite una acción de representación en el Estado miembro en el que haya sido designada, dicha acción debe considerarse una acción de representación nacional, aun cuando se ejercite frente a un empresario domiciliado en otro Estado miembro o mediante dicha acción se represente a consumidores de varios Estados miembros. A fin de determinar el tipo de acción de representación que se ejercita, debe utilizarse como criterio determinante en qué Estado miembro se ejercita la acción de representación." Añade en el Considerando 3 que: "las entidades habilitadas de distintos Estados miembros deben poder unir fuerzas en una única acción de representación ante un único foro, de conformidad con las correspondientes normas en materia de competencia judicial." 
62. A diferencia de la base de datos estadounidense $P A C E R$, la perfilada por la Directiva señala únicamente que pueda accederse a "información general sobre las acciones de representación en curso y concluidas.". Como ha quedado explicado más arriba (IV.4), resulta crucial que los sucesivos litigantes en la misma acción puedan beneficiarse del discovery — con las oportunas anonimizaciones - llevado a cabo por los anteriores demandantes.

63. Sorprende, por tanto, tanto que el art. 14 sea opcional, como esta limitación de la información que debe estar accesible en las bases de datos electrónicas. Más aún, cuando la propia Directiva apunta simultáneamente en su Considerando 71 que:

"La cooperación y el intercambio de información entre entidades habilitadas de diferentes Estados miembros han demostrado ser útiles, especialmente a la hora de abordar infracciones transfronterizas. Es necesario mantener las medidas de desarrollo de las capacidades y cooperación, y ampliarlas a un mayor número de entidades habilitadas en el conjunto de la Unión, con el fin de aumentar el ejercicio de las acciones de representación con implicaciones transfronterizas."

64. En fin, dichas bases de datos electrónicas podrían incluirse en el Atlas Judicial Europeo en materia civi ${ }^{80}$ que, entre otros, permite la obtención y práctica de prueba en otros Tribunales de la UE ${ }^{81}$.

\section{Conclusiones}

65. La comparación en el ámbito del Derecho de consumo entre el pre-trial discovery estadounidense y las diligencias acceso a fuentes de prueba en España y en Alemania pone de manifiesto las debilidades del instrumento patrio, así como la necesidad de reforzar este mecanismo al transponer la Directiva 2020/1828 a nuestro ordenamiento.

66. La asimetría informativa entre los destinatarios de productos y servicios y los empresarios unida a la insuficiencia de los actuales instrumentos procesales para acceder a las fuentes de prueba en poder del empresario demandado tiene como resultado la indefensión en numerosos supuestos de los consumidores y usuarios dañados.

67. La transposición del art. 18 de la Directiva 2020/1828 es buena ocasión para reforzar el catálogo de diligencias de acceso posibles e incluir las que son habituales en el ordenamiento estadounidense y asegurar de este modo la tutela judicial efectiva (arts. 24.1 y $118 \mathrm{CE}$ ) de consumidores y usuarios.

68. La transposición del art. 14 de la Directiva 2020/1828, por su parte, brinda la oportunidad de mejorar las bases de datos electrónicas de cooperación judicial para las acciones representativas en defensa de intereses colectivos de consumidores y usuarios de forma que los sucesivos litigantes puedan beneficiarse de las diligencias ya efectuadas por anteriores actores.

\footnotetext{
${ }^{80}$ P. GotTwald, «Das Europäische Justizielle Netz», en H. NAGEL, P. GotTwald (eds.) Internationales Zivilprozessrecht, 8 , Otto Schmidt, Köln, 2020, nn. 7.76-7.81.

${ }^{81}$ Cfr. Reglamento (CE) n ${ }^{\circ}$ 1206/2001 del Consejo, de 28 de mayo de 2001, relativo a la cooperación entre los órganos jurisdiccionales de los Estados miembros en el ámbito de la obtención de pruebas en materia civil o mercantil.
} 